\title{
Neurosurgical decision making: personal and professional preferences
}

\author{
Omar Tanweer, MD, ${ }^{1}$ Taylor A. Wilson, MD, ${ }^{1}$ Stephen P. Kalhorn, MD, ${ }^{2}$ John G. Golfinos, MD, ${ }^{1}$ \\ Paul P. Huang, MD, ${ }^{1}$ and Douglas Kondziolka, MD ${ }^{1}$ \\ 1Department of Neurosurgery, New York University, New York, New York; and 2Department of Neurosurgery, Medical University \\ of South Carolina, Charleston, South Carolina
}

\begin{abstract}
OBJECT Physicians are often solicited by patients or colleagues for clinical recommendations they would make for themselves if faced by a clinical situation. The act of making a recommendation can alter the clinical course being taken. The authors sought to understand this dynamic across different neurosurgical scenarios by examining how neurosurgeons value the procedures that they offer.
\end{abstract}

METHODS The authors conducted an online survey using the Congress of Neurological Surgeons listserv in May 2013. Respondents were randomized to answer either as the surgeon or as the patient. Questions encompassed an array of distinct neurosurgical scenarios. Data on practice parameters and experience levels were also collected.

RESULTS Of the 534 survey responses, 279 responded as the "neurosurgeon" and 255 as the "patient." For both vestibular schwannoma and arteriovenous malformation management, more respondents chose resection for their patient but radiosurgery for themselves ( $p=0.002$ and $p=0.001$, respectively). Aneurysm coiling was chosen more often than clipping, but those whose practice was $\geq 30 \%$ open cerebrovascular neurosurgery were less likely to choose coiling. Overall, neurosurgeons who focus predominantly on tumors were more aggressive in managing the glioma, vestibular schwannoma, arteriovenous malformation, and trauma. Neurosurgeons more than 10 years out of residency were less likely to recommend surgery for management of spinal pain, aneurysm, arteriovenous malformation, and trauma scenarios.

CONCLUSIONS In the majority of cases, altering the role of the surgeon did not change the decision to pursue treatment. In certain clinical scenarios, however, neurosurgeons chose treatment options for themselves that were different from what they would have chosen for (or recommended to) their patients. For the management of vestibular schwannomas, arteriovenous malformations, intracranial aneurysms, and hypertensive hemorrhages, responses favored less invasive interventions when the surgeon was the patient. These findings are likely a result of cognitive biases, previous training, experience, areas of expertise, and personal values.

http://thejns.org/doi/abs/10.3171/2014.11.JNS14400

KEY WORDS brain tumor; surgery; observation; survey; clinical care; radiosurgery; medical decision making; cognitive biases

$\mathrm{I}$ $\mathrm{N}$ most situations, physicians present several treatment options to patients who harbor complex medical problems. Neurosurgeons face these decision-making challenges on a daily basis and are usually prompted by the patient or the patient's family for their recommendations. Often, strong clinical data do not exist to provide an evidence-based recommendation that would fit the patient in question. Thus, recommendations may follow published evidentiary science modified by personal experience. Frequently, patients ask physicians what they would do for themselves if they were in the same situation. One of the goals of this hypothetical scenario is to give the questioned physician a personal connection to the problem in hopes of reducing treatment biases.

Some experts recommend that physicians avoid providing guidance based on personal decisions. ${ }^{10}$ Neurosurgical outcomes involve a level of function that affects persona, cognition, and mood, and the decision to perform surgery has major life implications. To examine the values surgeons place on different disorders, treatment options,

ABBREVIATIONS ACOA = anterior communicating artery; $\mathrm{AVM}=$ arteriovenous malformation; $\mathrm{IVH}=$ intraventricular hemorrhage; $\mathrm{PGY}=$ postgraduate year; $\mathrm{PT} 1-5=1-5$ years posttraining; $\mathrm{PT} 5-10=5-10$ years posttraining; $\mathrm{PT}>10=$ more than 10 years posttraining.

SUBMITTED February 20, 2014. ACCEPTED November 18, 2014.

INCLUDE WHEN CITING Published online January 9, 2015; DOI: 10.3171/2014.11.JNS14400.

DISCLOSURE The authors report no conflict of interest concerning the materials or methods used in this study or the findings specified in this paper. 
and potential outcomes, we surveyed a group of neurosurgeons on an array of specific neurosurgical scenarios, randomizing the questionnaire so that respondents were answering as either the surgeon recommending treatment or the patient him- or herself. Significant differences in answers between recommendations to a "patient" and choice for "self" may provide interesting insight into how we use available information in practical situations. Specifically, we seek to understand decision-making differences in neurosurgical scenarios when the role of the survey respondent is changed.

\section{Methods}

A survey was created with 7 neurosurgical scenarios, reviewed by the Education Committee of the Congress of Neurological Surgeons and was distributed to their membership listserv via email (see Appendix and Table 1). The survey respondents were randomized to receive one of 2 surveys. In one survey, the respondents were asked what they would choose to receive if they were the patients in each scenario. In the other survey, the respondents were asked what they would do as the surgeons who were making the recommendation. The surveys were otherwise identical.

All respondents were asked to record their level of experience, geographic location, and practice type. The level of experience was divided into 5 categories: junior resident (postgraduate year [PGY] 1-3), senior resident (PGY>3), 1-5 years posttraining (PT1-5), 5-10 years posttraining (PT5-10), and more than 10 years posttraining $(\mathrm{PT}>10)$. Practice locations were analyzed by regions (Northeast, Southeast, Northwest, Southwest, and Midwest) and were also grouped into coasts (Northeast, Southeast, Northwest, and Southwest) versus the Midwest, and Northeast versus the rest of the country (Midwest, Southwest, Northwest, and Southwest) for analysis. Practice type was either private practice or academic. Respondents were also asked to quantify the percentage of their practice that involved spine/peripheral nerve, tumor, open cerebrovascular, endovascular, pediatrics, and functional/pain. Respondents whose practices comprised $\geq 30 \%$ of any subfield were considered "focused" in that area, and their responses were compared with those of the other respondents.

Question 1 (epidural hematoma in a young patient with mass effect) was included as a control question for which one answer was considered the appropriate treatment.

\section{TABLE 1. Description of questions in the survey*}

\begin{tabular}{cl}
\hline $\begin{array}{c}\text { Question } \\
\text { No. }\end{array}$ & \multicolumn{1}{c}{ Subject Matter } \\
\hline 1 & Epidural hematoma causing mass effect \\
\hline 2 & Lt low-grade glioma in eloquent cortex \\
\hline 3 & Rt 1.5-cm vestibular schwannoma w/ diminished hearing \\
\hline 4 & Grade 1 spondylolisthesis at L4-5, back pain \\
\hline 5 & 6-mm incidentally found ACoA aneurysm \\
\hline 6 & Rt 1.5-cm temporal AVM w/ headaches \\
\hline 7 & Elderly patient w/ a It thalamic hemorrhage \& IVH \\
\hline
\end{tabular}

* See Appendix for full survey.
For Question 2 (elderly patient with a low-grade glioma), the answers were grouped into treatment (biopsy of lesion with chemotherapy/radiation, maximal safe resection with chemotherapy/radiation, chemotherapy only, radiation therapy only, or biopsy only) versus no treatment (comfort measures only). Of the respondents who chose treatment, responses were further subdivided based upon whether the treatment approach was conservative (biopsy of lesion with chemotherapy/radiation, chemotherapy only, radiation therapy only, or biopsy only) versus aggressive (maximal safe resection with chemotherapy/radiation therapy).

For Question 3 (young patient with a $1.5-\mathrm{cm}$ vestibular schwannoma [acoustic neuroma]), answers were grouped into treatment (resection via translabyrinthine or retrosigmoid approach or radiosurgery) versus no treatment (observation and medical management of vertigo). Of the respondents who chose treatment, the responses were further subdivided based on whether the treatment choice was conservative (radiosurgery) versus aggressive (translabyrinthine or retrosigmoid approach). For Question 4 (Grade 1 spondylolisthesis with back pain), answers were grouped into conservative (medical pain control and physical therapy) versus aggressive (posterolateral instrumented fusion with transforaminal interbody fusion, posterolateral instrumented fusion alone, lateral interbody fusion, or lateral interbody fusion with posterior instrumentation).

For Question 5 (middle-aged patient with a 6-mm anterior communicating artery [ACoA] aneurysm), answers were grouped into treatment (microsurgical clipping and coil embolization) versus no treatment. Of the respondents who chose treatment, their responses were further analyzed comparing those who chose microsurgical clipping versus those who chose coil embolization. For Question 6 (young patient with a right temporal $1.5-\mathrm{cm}$ arteriovenous malformation $[\mathrm{AVM}]$ ), answers were grouped into treatment (embolization followed by resection, radiosurgery, embolization alone, or resection alone) versus no treatment (observation). Of the respondents who chose treatment, their responses were further subdivided into conservative (radiosurgery) versus aggressive (embolization followed by resection, embolization alone, or resection alone). For Question 7 (elderly patient with left thalamic and intraventricular hemorrhage [IVH]), answers were grouped into intervention (evacuation of hematoma or ventriculostomy) versus no intervention (comfort measures only or medical critical care management). Of the respondents who chose intervention, their responses were further analyzed comparing those who chose evacuation of hematoma versus ventriculostomy.

All data were analyzed using SPSS (versions 20 and 22, IBM). Univariate analysis was performed on all groups and subgroups using the chi-square test for independence. Multivariate logistic regression analysis was performed on each question to characterize those variables associated with significant differences in responses between groups. Variables included in the multivariate analysis are respondent type (self vs surgeon offering recommendation), level of experience, practice location, practice type, practice focus (practices comprised $\geq 30 \%$ 
of any subfield vs practices $<30 \%$ of any subfield) for spine/peripheral nerve, tumor, open cerebrovascular, endovascular, pediatrics, and functional/pain. A p value $\leq$ 0.05 was considered significant.

\section{Results}

\section{Comparison of Neurosurgeons' Treatment Choice for Their Patients Versus Themselves}

A total of 534 neurosurgeons completed the survey. The survey link was successfully delivered to 2714 email addresses, yielding a response rate of $19.7 \%$. Of those surveyed, 279 were randomized to answer the survey from the perspective of the surgeon recommending treatment and 255 from the perspective of the patient. See Table 2 for respondent demographics. There was no statistical difference between the two groups. In a subanalysis, there

TABLE 2. Respondent demographics of those answering the survey as the surgeon or as the patient

\begin{tabular}{|c|c|c|c|}
\hline Variable & $\begin{array}{l}\text { Role as } \\
\text { Surgeon }\end{array}$ & $\begin{array}{l}\text { Role as } \\
\text { Patient }\end{array}$ & $p$ Value \\
\hline Experience & & & 0.127 \\
\hline Resident & $7.8 \%$ & $7.1 \%$ & \\
\hline PT1-5 & $10.0 \%$ & $15.3 \%$ & \\
\hline PT5-10 & $11.0 \%$ & $14.5 \%$ & \\
\hline $\mathrm{PT}>10$ & $71.2 \%$ & $63.1 \%$ & \\
\hline Geography & & & 0.539 \\
\hline Northeast & $22.4 \%$ & $20.8 \%$ & \\
\hline Southeast & $27.0 \%$ & $28.2 \%$ & \\
\hline Midwest & $21.7 \%$ & $26.3 \%$ & \\
\hline Northwest & $8.9 \%$ & $5.9 \%$ & \\
\hline Southwest & $19.9 \%$ & $18.8 \%$ & \\
\hline Practice type & & & 0.213 \\
\hline Private & $64.4 \%$ & $58.8 \%$ & \\
\hline Academic & $35.6 \%$ & $41.2 \%$ & \\
\hline Spine/Peripheral Nerve & & & 0.920 \\
\hline$<30 \%$ & $24.6 \%$ & $23.9 \%$ & \\
\hline$\geq 30 \%$ & $75.4 \%$ & $76.1 \%$ & \\
\hline Tumor & & & 0.156 \\
\hline$<30 \%$ & $73.0 \%$ & $67.1 \%$ & \\
\hline$\geq 30 \%$ & $27.0 \%$ & $32.9 \%$ & \\
\hline Open CV & & & 0.205 \\
\hline$<30 \%$ & $87.9 \%$ & $91.4 \%$ & \\
\hline$\geq 30 \%$ & $12.1 \%$ & $8.6 \%$ & \\
\hline Endovascular & & & 0.537 \\
\hline$<30 \%$ & $96.1 \%$ & $94.9 \%$ & \\
\hline$\geq 30 \%$ & $3.9 \%$ & $5.1 \%$ & \\
\hline Pediatrics & & & 1.000 \\
\hline$<30 \%$ & $90.4 \%$ & $90.2 \%$ & \\
\hline$\geq 30 \%$ & $9.6 \%$ & $9.8 \%$ & \\
\hline Functional/pain & & & 0.873 \\
\hline$<30 \%$ & $92.5 \%$ & $92.2 \%$ & \\
\hline$\geq 30 \%$ & $7.5 \%$ & $7.8 \%$ & \\
\hline
\end{tabular}

was a trend toward increased percentage of PT $>10$ respondents in the group taking the survey as the surgeon, compared with the group taking the survey as the patient $(p=0.06)$. In addition, no geographic differences were noted when comparing coasts $(\mathrm{p}=0.225)$ or comparing Northeast with all other locations $(\mathrm{p}=0.675)$.

Question 1 (epidural hematoma) was designed as a control question. The majority of neurosurgeons chose craniotomy for evacuation for their patient $(98 \%)$ as well as for themselves (98.9\%), and there was no difference between choices $(\mathrm{p}=0.490)$.

In the clinical scenario for management of a low-grade glioma, the majority of neurosurgeons chose treatment over no treatment; the recommendation for treatment was similar whether deciding for the patient or for "self" ( $p$ $=0.452$ ). Among the treatment options for the low-grade glioma, the majority chose the more aggressive option (resection) with no differences when deciding for the patient versus "self" $(p=0.172)$. In the management of a vestibular schwannoma, the respondents opted for treatment over conservative management in both surveys ( $p$ $=0.091$ ). However, among respondents who chose treatment, the majority of neurosurgeons recommended resection for their patients $(58.4 \%)$, but chose radiosurgery for themselves $(55.3 \%, \mathrm{p}=0.002$; Table 3$)$.

In Question 4 (spondylolisthesis management), the majority of neurosurgeons chose observation (no intervention) for their patients and for themselves ( $p=0.672$; Table 4).

The majority of respondents chose coiling for both their patients and themselves in the ACoA aneurysm scenario. Slightly more neurosurgeons chose coiling for themselves than for their patients; however, this difference only approached statistical significance $(80.5 \%$ vs $72.7 \%, \mathrm{p}=$ 0.056; Table 5). For the temporal AVM in Question 6, the majority of neurosurgeons chose treatment of the lesion for both their patient and themselves $(90.4 \%$ and $85.2 \%$, respectively, $\mathrm{p}=0.083$ ). Of those who chose treatment of

TABLE 3. Comparison of neurosurgeons' choice of radiosurgery versus resection for a vestibular schwannoma, Question 3

\begin{tabular}{cccc}
\hline Variable & Radiosurgery & Resection & p Value \\
\hline Role in survey & & & 0.002 \\
\hline As patient & $55.3 \%$ & $44.7 \%$ & \\
\hline As surgeon & $41.6 \%$ & $58.4 \%$ & \\
\hline Experience & & & 0.152 \\
\hline PGY1-PT 10 & $43.8 \%$ & $56.2 \%$ & \\
\hline PT>10 & $50.9 \%$ & $49.1 \%$ & \\
\hline Practice type & & & 0.530 \\
\hline Private & $37.1 \%$ & $47.9 \%$ & \\
\hline Academic & $44.2 \%$ & $57.1 \%$ & \\
\hline Tumor & & & 0.041 \\
\hline$<30 \%$ & $51.7 \%$ & $48.3 \%$ & \\
\hline $\begin{array}{l}230 \% \\
\text { Functional/pain }\end{array}$ & $41.4 \%$ & $58.6 \%$ & \\
\hline$<30 \%$ & & & \\
\hline$\geq 30 \%$ & $61.5 \%$ & $52.5 \%$ & \\
\hline
\end{tabular}


TABLE 4. Comparison of neurosurgeons' choice of intervention versus conservative management for a lumbar spondylolisthesis, Question 4

\begin{tabular}{lccc}
\hline \multicolumn{1}{c}{ Variable } & Intervention & $\begin{array}{c}\text { Conservative } \\
\text { Management }\end{array}$ & p Value \\
\hline Role in survey & & & 0.672 \\
\hline As patient & $22.5 \%$ & $77.5 \%$ & \\
\hline As surgeon & $20.9 \%$ & $79.1 \%$ & \\
\hline Experience & & & 0.023 \\
\hline PGY1-PT 10 & $28.0 \%$ & $72.0 \%$ & \\
\hline PT>10 & $18.8 \%$ & $81.2 \%$ & \\
\hline Practice Type & & & 1.000 \\
\hline Private & $21.6 \%$ & $78.4 \%$ & \\
\hline Academic & $21.9 \%$ & $78.1 \%$ & \\
\hline Spine/peripheral nerve & & & 0.082 \\
\hline$<30 \%$ & $16.0 \%$ & $84.0 \%$ & \\
\hline$\geq 30 \%$ & $23.5 \%$ & $76.8 \%$ & \\
\hline
\end{tabular}

the AVM, neurosurgeons were significantly more likely to choose aggressive interventions for their patient than for themselves (70.7\% vs 53\%, $\mathrm{p}=0.001$; Table 6$)$.

When asked to consider the scenario of an elderly patient with a left thalamic hemorrhage and IVH, neurosurgeons were significantly more likely to choose treatment for their patient than for themselves $(82.7 \%$ vs $64.7 \%$, p < 0.001 , Table 7). Of those who chose treatment, the majority chose ventriculostomy (99.2\%) rather than a craniotomy.

TABLE 5. Comparison of neurosurgeons' choice of clipping versus coiling for an $\mathrm{ACOA}$ aneurysm, Question 5

\begin{tabular}{|c|c|c|c|}
\hline Variable & Clipping & Coiling & $p$ Value \\
\hline Role in survey & & & 0.056 \\
\hline As patient & $19.5 \%$ & $80.5 \%$ & \\
\hline As surgeon & $27.3 \%$ & $72.7 \%$ & \\
\hline Experience & & & 0.465 \\
\hline PGY1-PT 10 & $25.7 \%$ & $74.3 \%$ & \\
\hline PT>10 & $22.2 \%$ & $77.8 \%$ & \\
\hline Practice Type & & & 0.165 \\
\hline Private & $21.0 \%$ & $79.0 \%$ & \\
\hline Academic & $27.1 \%$ & $72.9 \%$ & \\
\hline Spine/Peripheral Nerve & & & 0.002 \\
\hline$<30 \%$ & $34.9 \%$ & $65.1 \%$ & \\
\hline$\geq 30 \%$ & $19.6 \%$ & $80.4 \%$ & \\
\hline Tumor & & & 0.003 \\
\hline$<30 \%$ & $19.1 \%$ & $80.9 \%$ & \\
\hline$\geq 30 \%$ & $32.4 \%$ & $67.6 \%$ & \\
\hline Open CV & & & 0.001 \\
\hline$<30 \%$ & $20.9 \%$ & $79.1 \%$ & \\
\hline$\geq 30 \%$ & $42.9 \%$ & $57.1 \%$ & \\
\hline Endovascular & & & 0.800 \\
\hline$<30 \%$ & $23.2 \%$ & $76.8 \%$ & \\
\hline$\geq 30 \%$ & $26.1 \%$ & $73.9 \%$ & \\
\hline
\end{tabular}

TABLE 6. Comparison of neurosurgeons' choice of conservative (radiosurgery) versus aggressive (surgery, embolization, or both) treatment for an AVM, Question 6

\begin{tabular}{cccc}
\hline Variable & Conservative & Aggressive & p Value \\
\hline Role in survey & & & 0.001 \\
\hline As patient & $45.0 \%$ & $53.0 \%$ & \\
\hline As surgeon & $29.3 \%$ & $70.7 \%$ & \\
\hline Experience & & & 0.127 \\
\hline PGY1-PT 10 & $32.3 \%$ & $67.7 \%$ & \\
\hline PT>10 & $39.9 \%$ & $60.1 \%$ & \\
\hline Practice Type & & & 0.113 \\
\hline Private & $40.4 \%$ & $59.6 \%$ & \\
\hline Academic & $32.6 \%$ & $67.4 \%$ & \\
\hline Tumor & & & 0.046 \\
\hline$<30 \%$ & $40.4 \%$ & $59.6 \%$ & \\
\hline$\geq 30 \%$ & $30.2 \%$ & $69.8 \%$ & \\
\hline Open CV & & & 0.637 \\
\hline$<30 \%$ & $37.7 \%$ & $62.3 \%$ & \\
\hline$\geq 30 \%$ & $33.3 \%$ & $66.7 \%$ & \\
\hline Endovascular & & & 0.646 \\
\hline$<30 \%$ & $37.0 \%$ & $63.0 \%$ & \\
\hline$\geq 30 \%$ & $42.9 \%$ & $57.1 \%$ & \\
\hline
\end{tabular}

\section{Comparison of Neurosurgeons' Treatment Choice Based on Experience}

For Question 4 (spondylolisthesis), PT $>10$ neurosurgeons were significantly more likely to choose observation (no intervention) than residents and PT1-10 neurosurgeons $(81.2 \%$ vs $72.0 \%, p=0.023$; Table 4$)$. In the aneurysm scenario (Table 5), PT>10 neurosurgeons were significantly more likely to choose treatment for their patient compared with less experienced surgeons $(90.5 \%$ vs $80.2 \%, \mathrm{p}=0.032)$, but not for themselves $(81.8 \%$ vs $84.0 \%, p=0.718)$

For the AVM in Question 6, residents or PT1-10 surgeons were significantly more likely to recommend AVM treatment $(94 \%)$ than PT $>10$ neurosurgeons $(84.7 \%)(\mathrm{p}=$ $0.002)$. In the case of a thalamic hemorrhage and IVH, residents and PT1-10 surgeons were significantly more

TABLE 7. Comparison of neurosurgeons' choice of treatment versus no treatment for a thalamic hemorrhage and IVH, Question 7

\begin{tabular}{cccc}
\hline Variable & Treatment & No Treatment & p Value \\
\hline Role in survey & & & $<0.001$ \\
\hline As patient & $64.7 \%$ & $35.3 \%$ & \\
\hline As surgeon & $82.7 \%$ & $17.3 \%$ & \\
\hline Experience & & & 0.127 \\
\hline PGY1-PT10 & $80.4 \%$ & $19.6 \%$ & \\
\hline PT>10 & $70.0 \%$ & $30.0 \%$ & \\
\hline Practice Type & & & 0.053 \\
\hline Private & $70.3 \%$ & $29.7 \%$ & \\
\hline Academic & $78.1 \%$ & $21.9 \%$ & \\
\hline
\end{tabular}


likely to choose treatment $(80.4 \%)$ than PT $>10$ neurosurgeons $(70.0 \%, \mathrm{p}=0.014)$.

\section{Multivariate Analysis of Factors Affecting Response}

In Question 1, our control scenario, none of the recorded survey parameters correlated with the chosen responses. In Question 2, there were no significant predictors for recommending treatment, since the vast majority of respondents chose some form of management. The strongest predictor of choosing aggressive (maximal resection plus chemotherapy and radiation therapy) versus conservative treatment was practice subtype $\geq 30 \%$ tumor neurosurgery (OR 1.561 [95\% CI 1.043-2.338]; $\mathrm{p}=$ 0.030 ). Practice subtype $\geq 30 \%$ tumor neurosurgery was also the strongest predictor of choosing aggressive versus conservative treatment for "self" (OR 1.891 [95\% CI $1.058-3.380] ; \mathrm{p}=0.032$ ).

For Question 3, the strongest predictors among all respondents for choosing resection versus radiosurgery for the vestibular schwannoma were practice subtype $\geq 30 \%$ tumor neurosurgery (OR 1.523 [95\% CI 1.011-2.294]; $\mathrm{p}=$ 0.044 ), practice subtype $\geq 30 \%$ endovascular neurosurgery (OR 3.666 [95\% CI 1.273-10.555]; $\mathrm{p}=0.016$ ), and practice subtype < 30\% functional and pain (OR 2.079 [95\% CI 1.036-4.167]; $\mathrm{p}=0.039)$. When subdivided by survey type ("self" vs patient), there were no significant predictors for choosing resection versus radiosurgery for "self." However, academic practice setting (OR 1.803 [95\% CI 1.0403.126]; $\mathrm{p}=0.036$ ), practice subtype $<30 \%$ functional and pain (OR 3.236 [95\% CI 1.124-9.346]; $\mathrm{p}=0.029$ ), and practice subtype $\geq 30 \%$ endovascular neurosurgery (OR 11.883 [95\% CI 1.391-101.549]; $\mathrm{p}=0.024$ ) were significant predictors for recommending resection for patients.

For the aneurysm in Question 5, the strongest predictors of choosing coiling versus clipping among all respondents were practice subtype $<30 \%$ tumor neurosurgery (OR 1.757 [95\% CI 1.093-2.832]; $\mathrm{p}=0.020$ ), practice subtype $<30 \%$ endovascular neurosurgery (OR $2.273[95 \%$ CI 1.195-4.329]; $\mathrm{p}=0.012$ ), and practice subtype $<30 \%$ pediatric neurosurgery (OR 2.053 [95\% CI 1.032-4.082]; $\mathrm{p}=0.040$ ). When subdivided by survey type ("self" vs patient), there were no significant predictors for choosing coiling versus clipping for "self," but significant predictors for choosing coiling for patients when practice subtype $<30 \%$ open cerebrovascular neurosurgery (OR 6.993 [95\% CI 2.288-21.277]; $\mathrm{p}=0.001$ ) and practice subtype $<30 \%$ pediatric neurosurgery (OR 2.667 [95\% CI 1.019-6.993]; $p=0.046$ ). Surgeons with $\geq 30 \%$ open cerebrovascular practice focus favored clipping (43\%) compared with those with a $<30 \%$ focus $(21 \%)$, but the majority of surgeons with $\geq 30 \%$ open cerebrovascular practice still chose coiling over clipping $(57 \%, \mathrm{p}=0.001)$.

For the AVM in Question 6, the strongest predictor among all respondents for choosing resection was practice subtype $\geq 30 \%$ tumor neurosurgery (OR $1.564[95 \%$ CI 1.022-2.395]; $\mathrm{p}=0.040$ ). When subdivided by survey type ("self" vs patient), the strongest predictor for choosing resection for "self" was practice subtype $\geq 30 \%$ tumor neurosurgery (OR 1.842 [95\% CI 1.012-3.351]; $\mathrm{p}=$ $0.045)$. The strongest predictors for choosing resection for their patient were practice subtype $\geq 30 \%$ open cerebro- vascular neurosurgery (OR 6.513 [95\% CI 1.119-37.914]; $\mathrm{p}=0.032), \mathrm{PT}>10$ (OR 2.237 [95\% CI 1.185-4.220]; $\mathrm{p}=$ 0.013 ), and practice subtype $<30 \%$ endovascular neurosurgery (OR 5.025 [95\% CI 1.117-22.727]; $\mathrm{p}=0.035$ ).

In the analysis for Question 7 (thalamic hemorrhage and IVH), the strongest predictor for the surgeons' choosing treatment for their patient was practice subtype $\geq 30 \%$ tumor neurosurgery (OR 2.453 [95\% CI 1.081-5.564]; $\mathrm{p}=$ 0.032 ). Of those who chose treatment, there were no significant predictors for choosing craniotomy versus ventriculostomy when subdivided by practice type as almost all respondents chose ventriculostomy.

No significant trends or predictors were found when testing for differences among geography of survey respondents.

\section{Discussion}

Our study shows that, in the majority of cases, altering the role of the surgeon did not change the decision to pursue treatment or not. In certain clinical scenarios, however, neurosurgeons did choose treatment options for themselves that were different from what they would have recommended for their patients. Medical decision making is a complex and multifactorial process. A variety of cognitive biases, in addition to personal experiences, prior training, and medicolegal considerations, play a role in decision making. ${ }^{3,7}$ A physician recommending treatment faces biases that are different from those faced by an individual who is choosing a treatment. Zikmund-Fisher et al. showed differences in responses among groups of nonmedical participants who were asked to choose treatment options from the perspective of a physician or a patient. ${ }^{16}$ A change in the decider's role has a major impact on the choices that are made, and this phenomenon is reflected in the results seen in our survey. ${ }^{13}$

One recurring theme illustrated by our cases is the balance between procedural invasiveness and durability of a cure. For example, studies have shown that endovascular coiling of intracranial aneurysms has a lower periprocedural morbidity than surgical clipping, but is also associated with a lower rate of complete occlusion. ${ }^{11}$ In the clinical scenarios in our survey, neurosurgeons chose the minimally invasive treatment more often for themselves, potentially valuing less risk over durability. This trend differs from that in a prior study in which physicians were more likely to choose a hypothetically riskier and more invasive procedure for themselves if it resulted in a higher cure rate. ${ }^{14}$ Our study may have produced different results for several reasons. For one, the use of common neurosurgical scenarios and familiar treatment options likely creates a decision process different from that of dealing with hypothetical illnesses and treatments. More importantly, the discrepancy in our findings likely results from the background of survey participants, that is, neurosurgical versus general medical. Neurosurgeons may have a set of values and personal priorities that is different from those of other populations. For example, some complications may be career ending, warranting neurosurgeons to choose a less efficacious, but safer, treatment. This is described as loss aversion and is part of Drs. Kahneman and 
Tversky's Nobel Prize-winning work in prospect theory. ${ }^{8}$ In brief, it describes that when making decisions involving risk, individuals fear loss more than they desire gains. Our results show that neurosurgeons may be more loss or risk averse for themselves than for patients.

The dominant cognitive biases in medical decision making mainly pertain to reconciling the consequences of an adverse outcome from a decision against the benefits. Betrayal aversion dictates that harm from an intervention recommended by a trusted individual (a physician) is considered worse than the same harm from a random person or event (i.e., betrayal is not involved). ${ }^{3,9,14}$ This is similar in scope to omission bias, where harm from a specific action is perceived as worse than the same harm occurring from inaction. ${ }^{1,2}$ In contrast, neurosurgeons may sometimes place a higher priority on preventing recurrences and associate this with a higher level of failure than a complication as a result of the procedure.

With improved access to both general medical information and results from controlled trials, patient-physician communications have become increasingly sophisticated. Classically, 4 models of physician-patient relations have been described. ${ }^{6}$ These vary from a paternalistic model, which unilaterally places the responsibility of decision making with the physician, to the other extreme where factual information is presented with very little interpretation or guidance from the physician. When a patient asks, "Doctor, what would you do?" a distinct challenge is presented. Answering this question may breach patient autonomy; refusal to answer may lead to feelings of abandonment. ${ }^{10}$ It is important for both parties to understand that different sets of values, cognitive biases, and processes play a role in medical decision making. An understanding of the patient's value systems, priorities, and treatment options will likely lead to the "right" decision. ${ }^{12}$

Do neurosurgeons "practice what they preach?" Clearly, different biases play a role in the decision-making process from the perspective of the physician or the patient, and so the determination of "best treatment" needs context. It should not be assumed that one modality is superior if a physician chooses it for him- or herself. It also has been noted by several studies that doctors do not make "great" patients and they prefer to manage their own medical issues and sometimes do so poorly. ${ }^{4,5,15}$

\section{Limitations}

This study has several limitations inherent to studies interpreting data from surveys. The population of neurosurgeons who responded to this survey may not be representative of the population of neurosurgeons as a whole (responder bias). It is possible that some of the respondents answered the questions in one way, but in reality would recommend something different (response bias). This may occur because the respondent answers the survey at his or her leisure without having to consider patient care goals or family preferences. In reality, however, these outside influences often play a large role in the neurosurgical decision-making process.

Survey design can lead to framing bias, whereby the wording of a question may bias the responder to answer in a certain way. In addition, there was a trend $(p=0.06)$ of more experienced neurosurgeons in the group randomized to take the survey as the surgeon. This clearly can influence results; however, this difference is marginal and would not change the conclusion of our subanalyses overall.

\section{Conclusions}

There are several commonly encountered neurosurgical clinical scenarios where neurosurgeons would choose differently for themselves than for other people. These findings are likely a result of cognitive biases, previous training, areas of expertise, and personal values. It is important that the surgeon be aware of these decision-making biases to allow for appropriate interpretation of responses when asked by colleagues or patients to imagine him- or herself as the patient. The decision-making process is a very important aspect of neurosurgery, and previous studies exploring this are limited. This study serves as a framework for additional studies to explore particular aspects of the neurosurgical decision-making process. Ultimately, when making medical decisions, open communication with a patient about his or her wishes and goals will enable more satisfactory treatment decisions.

\section{Acknowledgments}

We thank Dr. Zoher Ghogawala, members of the Congress of Neurological Surgeons Education Committee, and Congress of Neurological Surgeons staff for assisting with this survey. We also acknowledge Poppy McLeod, PhD (Department of Communication, at Cornell University), for reviewing the survey questions prior to initiation of study.

\section{References}

1. Aberegg SK, Haponik EF, Terry PB: Omission bias and decision making in pulmonary and critical care medicine. Chest 128:1497-1505, 2005

2. Asch DA, Baron J, Hershey JC, Kunreuther H, Meszaros J, Ritov I, et al: Omission bias and pertussis vaccination. Med Decis Making 14:118-123, 1994

3. Bornstein BH,Emler AC: Rationality in medical decision making: a review of the literature on doctors' decision-making biases. J Eval Clin Pract 7:97-107, 2001

4. Chen JY, Tse EY, Lam TP, Li DK, Chao DV, Kwan CW: Doctors' personal health care choices: a cross-sectional survey in a mixed public/private setting. BMC Public Health 8:183, 2008

5. Clarke J, O'Sullivan Y, Maguire N: A study of self-care among Irish doctors. Ir Med J 91:175-176, 1998

6. Emanuel EJ, Emanuel LL: Four models of the physicianpatient relationship. JAMA 267:2221-2226, 1992

7. Ghaffarzadegan N, Epstein AJ, Martin EG: Practice variation, bias, and experiential learning in cesarean delivery: a data-based system dynamics approach. Health Serv Res 48:713-734, 2013

8. Kahneman D, Tversky A: Prospect theory: an analysis of decision under risk. Econometrica 47:263-292, 1979

9. Koehler JJ, Gershoff AD: Betrayal aversion: when agents of protection become agents of harm. Organ Behav Hum Decis Process 90:244-261, 2003

10. Minkoff H, Lyerly AD: "Doctor, what would you do?" Obstet Gynecol 113:1137-1139, 2009

11. Molyneux AJ, Kerr RS, Yu LM, Clarke M, Sneade M, Yarnold JA, et al: International subarachnoid aneurysm trial (ISAT) of neurosurgical clipping versus endovascular coiling in 2143 patients with ruptured intracranial aneurysms: a randomised comparison of effects on survival, dependency, seizures, rebleeding, subgroups, and aneurysm occlusion. Lancet 366:809-817, 2005 
12. Quill TE, Brody H: Physician recommendations and patient autonomy: finding a balance between physician power and patient choice. Ann Intern Med 125:763-769, 1996

13. Raymark PH: Accepting or rejecting medical treatment: a comparison of decisions made for self versus those made for a significant other. J Appl Soc Psychol 30:2409-2436, 2000

14. Ubel PA, Angott AM, Zikmund-Fisher BJ: Physicians recommend different treatments for patients than they would choose for themselves. Arch Intern Med 171:630-634, 2011

15. Wachtel TJ, Wilcox VL, Moulton AW, Tammaro D, Stein MD: Physicians' utilization of health care. J Gen Intern Med 10:261-265, 1995

16. Zikmund-Fisher BJ, Sarr B, Fagerlin A, Ubel PA: A matter of perspective: choosing for others differs from choosing for yourself in making treatment decisions. J Gen Intern Med 21:618-622, 2006

\section{Author Contributions}

Conception and design: all authors. Acquisition of data: all authors. Analysis and interpretation of data: all authors. Drafting the article: all authors. Critically revising the article: all authors. Reviewed submitted version of manuscript: all authors. Approved the final version of the manuscript on behalf of all authors: Tanweer. Statistical analysis: Wilson. Administrative/technical/ material support: Tanweer, Wilson.

\section{Supplemental Information}

Previous Presentation

Data in this paper were presented at the 82nd AANS Annual Scientific Meeting, April 5-9, 2014, in San Francisco, California, and have received the Robert Florin Resident Award in the Socioeconomic Section.

\section{Correspondence}

Omar Tanweer, Department of Neurosurgery, New York University, 462 First Ave., Ste. 7S4, New York, NY 10016. email: omar.tanweer@nyumc.org.

\section{Appendix}

\section{Introduction and Demographics:}

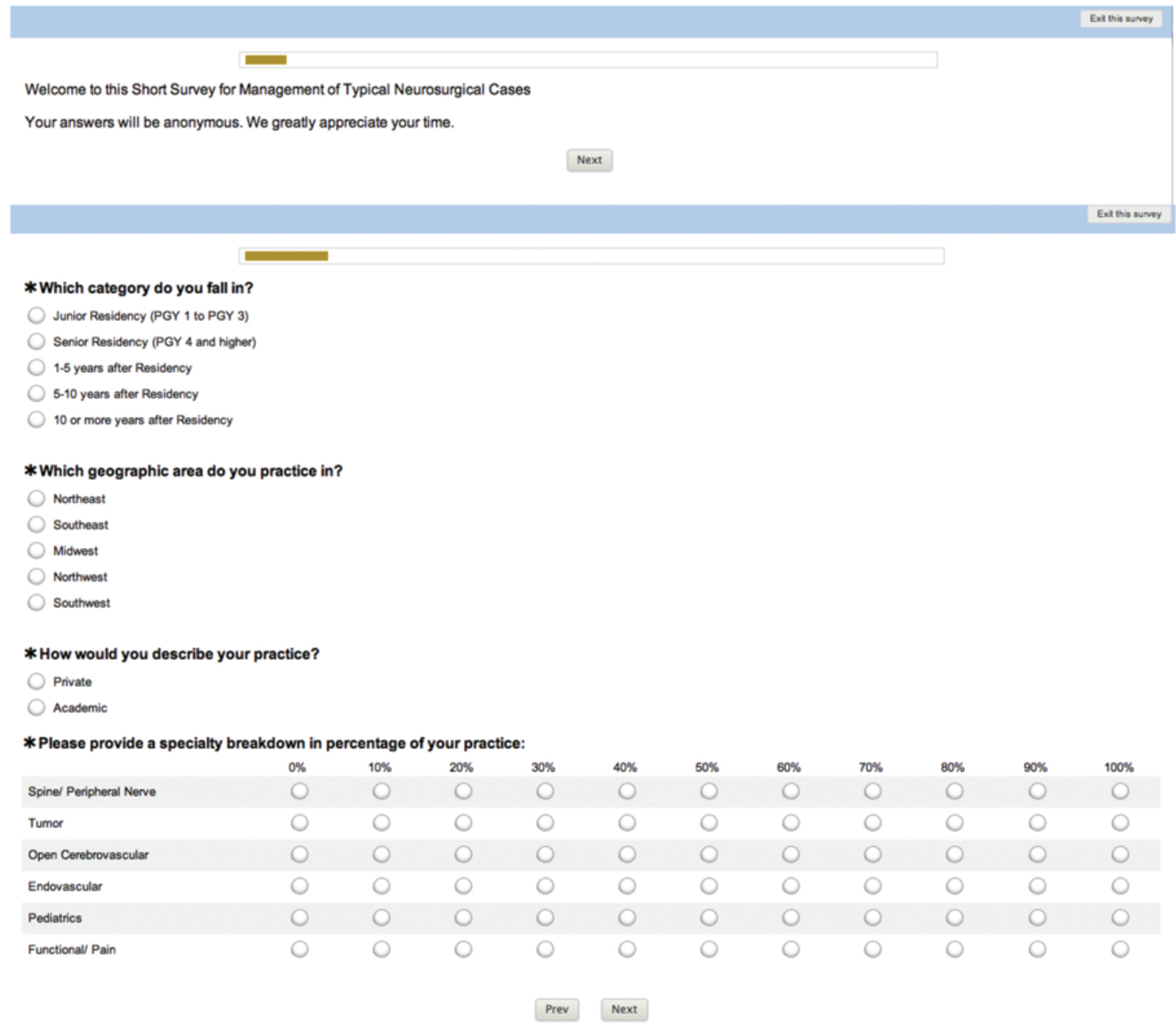




\section{Question \#1, Epidural Hematoma}
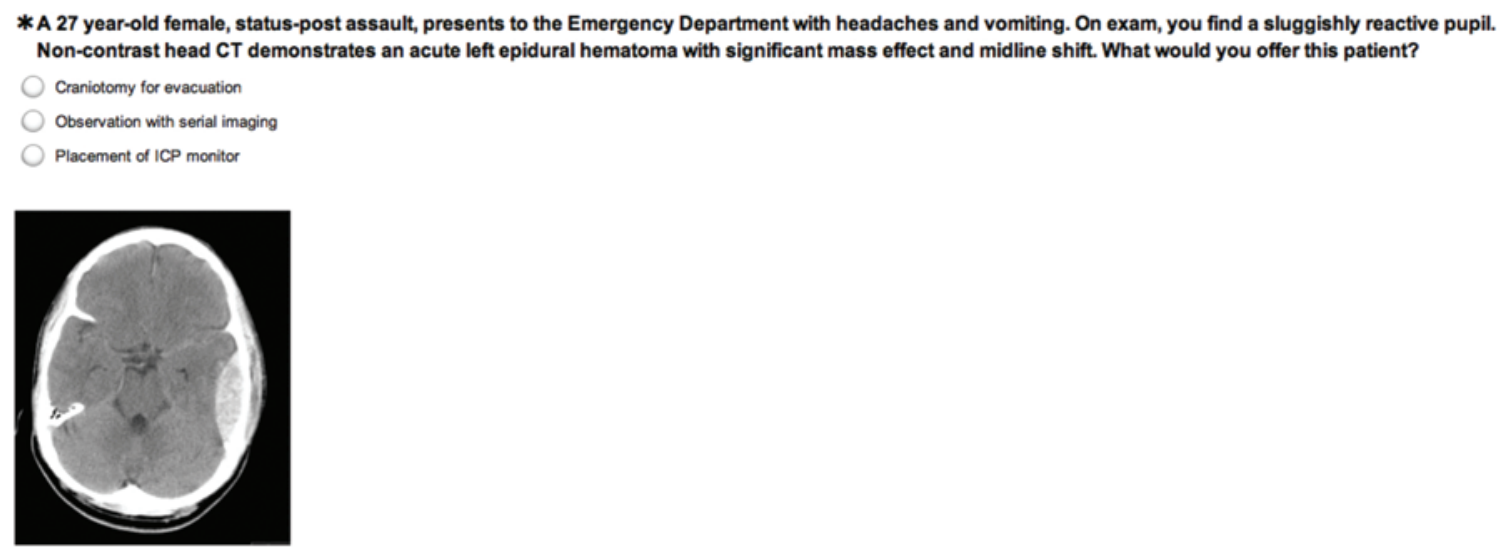

* You are 27 years old and status-post assault. You present with complaints of headache and vomiting to a nearby Emergency Department. On exam you have a sluggishly reactive pupil. Non-contrast head $\mathrm{CT}$ demonstrates an acute left epidural hematoma with significant mass effect and midline shift. What would you want done for yourself?

Craniotomy for evacuation

Observation with serial imaging

Placement of ICP monitor

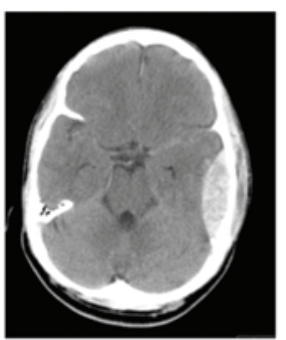




\section{Question \#2, Low-Grade Glioma}
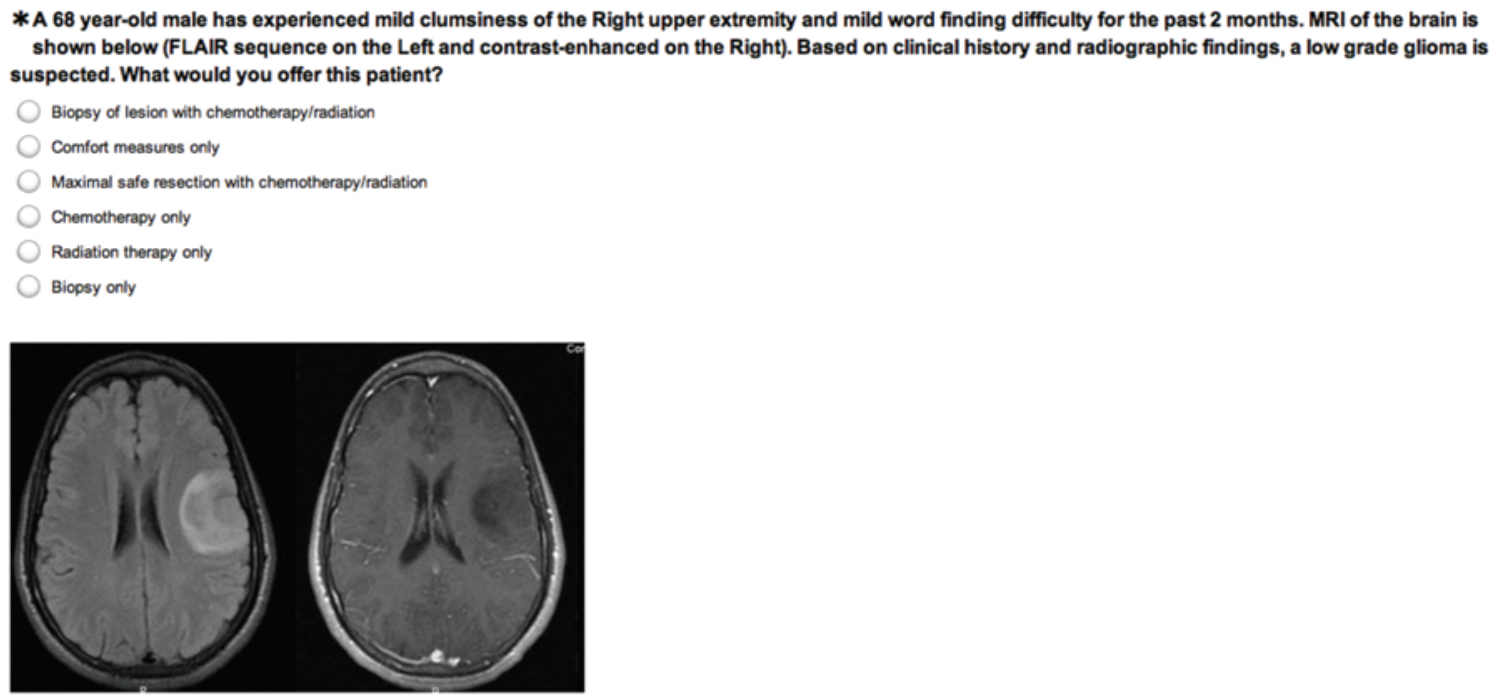

* You are 68 years old and have noticed mild clumsiness of the Right upper extremity and slight word finding difficulty for the past 2 months. Your MRI of the brain is shown below (FLAIR sequence on the Left and contrast-enchanced on the Right). Based on clinical history and radiographic findings, a low grade glioma is suspected. What would you want done for yourself?
Biopsy of lesion with chemotherapy/radiation
comfort measures only
Maximal safe resection with chemotherapy/radiation
Chemotherapy only
Radiation therapy only
Biopsy only

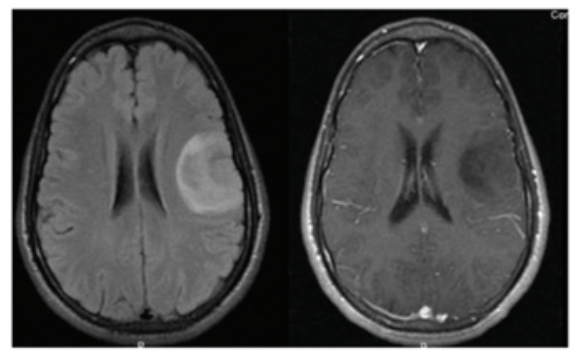




\section{Question \#3, Acoustic Neuroma (Vestibular Schwannoma)}

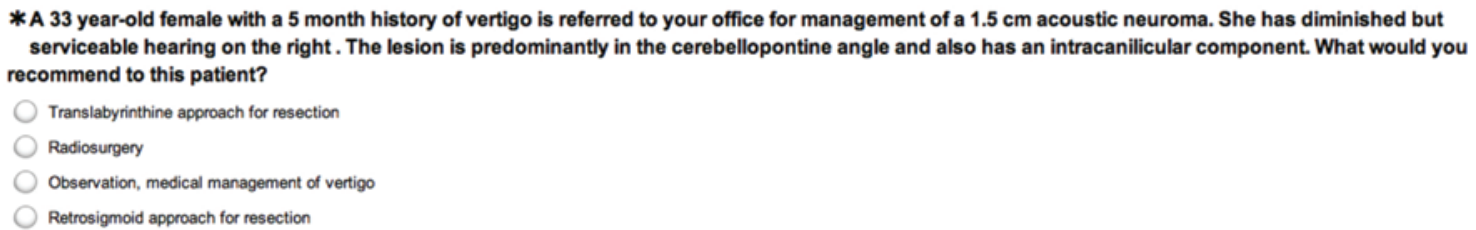
recommend to this patient?

Translabyrinthine approach for resection

Radiosurgery

Observation, medical management of vertigo

Retrosigmoid approach for resection

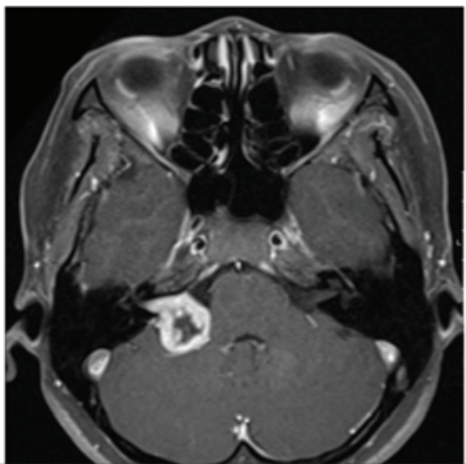

* You are 33 years old and have a 5 month history of vertigo and diminished but serviceable hearing on the right. You are found to have a $1.5 \mathrm{~cm}$ acoustic neuroma. The lesion is predominantly in the cerebellopontine angle and also has an intracanilicular component. What would you want for yourself?

Translabyrinthine approach for resection

Radiosurgery

Observation, medical management of vertigo

Retrosigmoid approach for resection

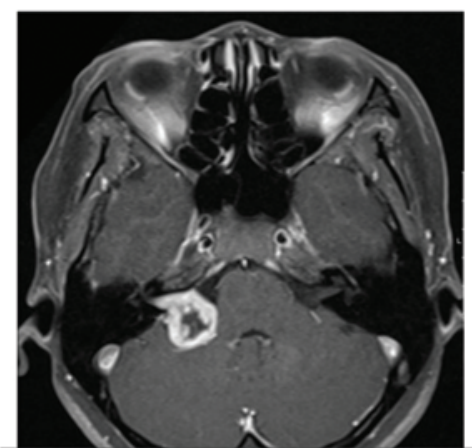


Question \# 4, Lumbar Grade I Spondylolisthesis

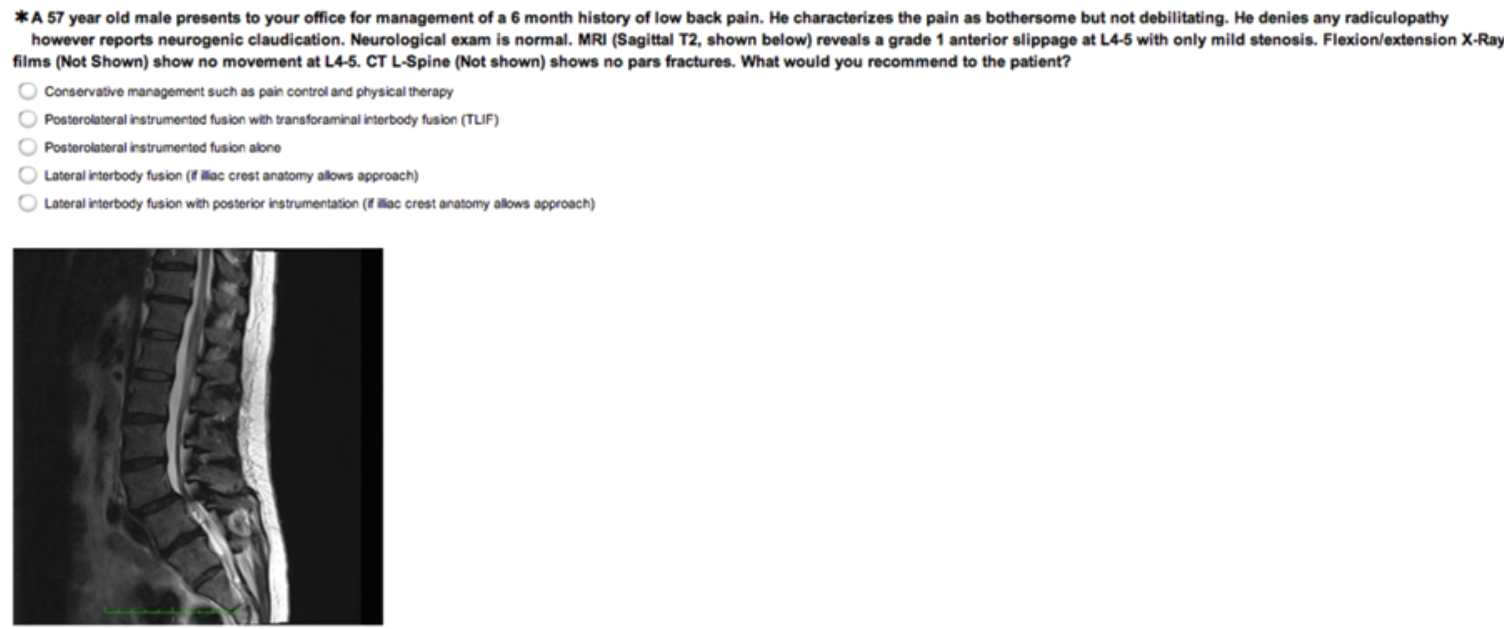

* You are 57 years old and have a 6 month history of low back pain. You characterize the pain as bothersome but not debilitating. You deny any radieulopathy however have neurogenic claudication. You have a normal neurological exam. MRI (Sagittal T2, shown below) reveals a grade 1 anterior slippage at L4-5 with only mild stenosis. Flexion/extension X-Ray films (Not Shown) show no movement at L4-5. CT L-Spine shows no pars fractures. What would you want done for yourself?

Conservative management such as pain control and physical therapy

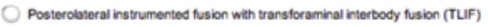

Posterobstoral hatrumentiod fusion alone

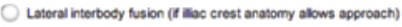

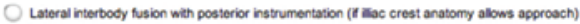

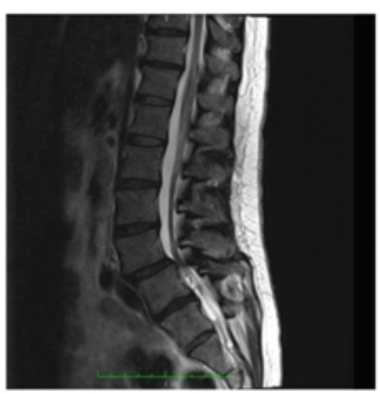




\section{Question \#5, ACoA (Acomm) Aneurysm}

*A 51 year-old male presents to your office for management of an aneurysm. He has a history of migraines and an aneurysm was found on MRI. A subsequent angiogram revealed an unruptured $6 \mathrm{~mm}$ Acomm aneurysm pointing superiorly. What would you recommend to this patient?

Microsurgical clipping

Observation with serial imaging

Coll embolization

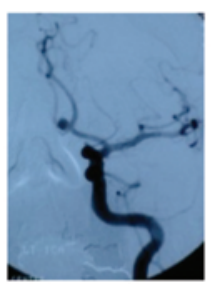

* You are 51 years old with a history of migraines. An MRI was done and revealed an incidental aneurysm. A subsequent angiogram showed an unruptured 6 mm left Acomm aneurysm pointing superiorly. What would you want done for yourself?

Microsurgical clipping

Observation with serial imaging

coil embolization

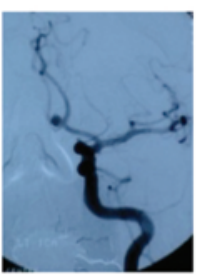




\section{Question \#6, AVM}
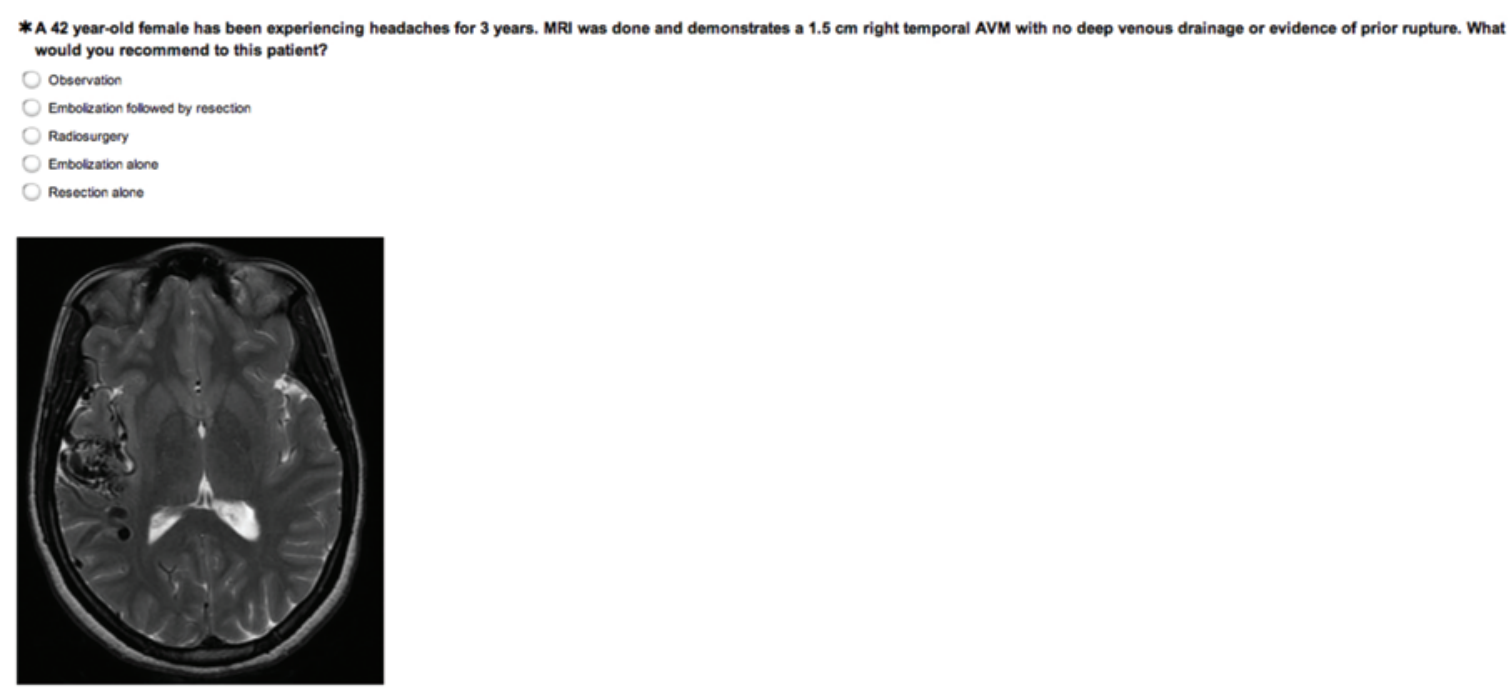

* You are 42 years old and have been experiencing headaches for 3 years. MRI demonstrates a $1.5 \mathrm{~cm}$ right temporal AVM with no deep venous drainage or evidence of prior rupture. What would you want done for yourself?

Observation

Embolzation followod by resection

Rasiosurgery

Emboleation alone

Resection alione

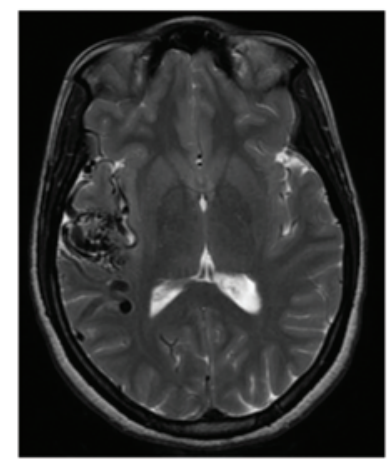




\section{Question \#7, Thalamic Hemorrhage and IVH}
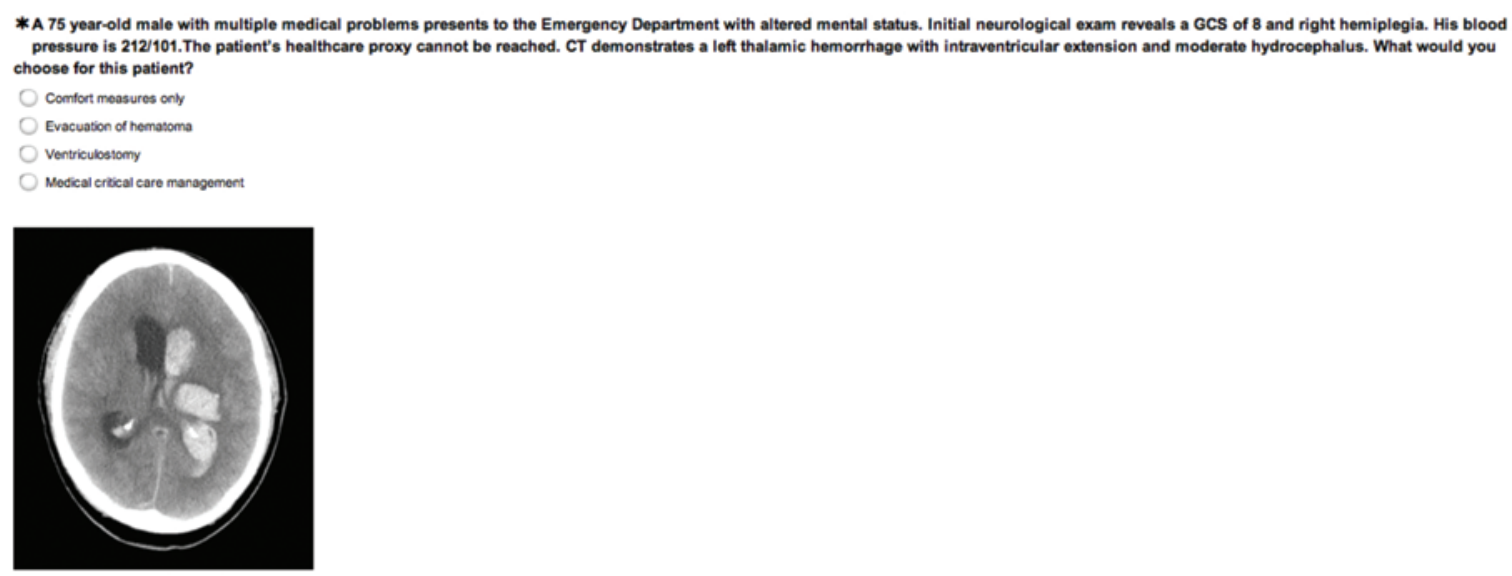

*You are 75 years old with multiple medical problems and brought to the ER with altered mental status. Initial neurological exam reveals a GCS of 8 and right hemiplegia, Blood pressure is $212 / 101$. Your healthcare proxy cannot be reached. CT demonstrates a left thalamic hemorrhage with intraventricular extension and moderate hydrocephalus. What would you want done for yourself?

Comfort measures only

Evacuation of homatoma

Venticulostomy

Mescal critical care management

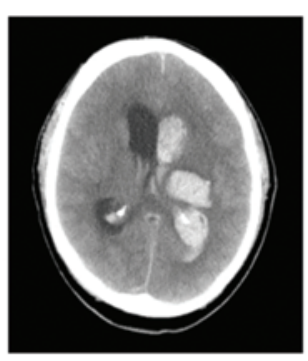

